\title{
Anti-oxidant and Anti-inflammatory Properties of Stem and Root Extracts of Cissus quadrangularis (Veldt Grape)
}

\author{
L. Dinesh Kumar ${ }^{1}$, R. Guna ${ }^{2}$, E. Abbirami ${ }^{3}$, N. Gayathri ${ }^{4}$, R. Karthik ${ }^{5}$ and T. Sivasudha ${ }^{6 *}$ \\ ${ }^{6}$ Associate Professor, ${ }^{1,2,3,4,5 \& 6}$ Department of Environmental Biotechnology, \\ Bharathidasan University, Tiruchirappalli, Tamil Nadu, India \\ *Corresponding Author \\ E-Mail: sudha@bdu.ac.in, sudacoli@yahoo.com
}

\begin{abstract}
Free radicals are unstable, highly reactive molecules, creates oxidative stress in our body by attacking healthy cells and tissue biomolecules. They are usually neutralized by the antioxidant mechanisms in our system. When the antioxidant mechanism fails to stabilize the radicals, we need external antioxidants to protect our cells from oxidative damage. The objective of present study is to evaluate the antioxidant and anti-inflammatory properties of stem and root extracts of the plant Cissus quadrangularis. Stem and root powders of $C Q$ was extracted with different solvent and they were tested against the synthetic free radical DPPH, ABTS, NO, $\mathrm{H}_{2} \mathrm{O}_{2}$ and FRAP with the reference standard BHT. The in vitro antiinflammatory activity assay was also performed for all the extracts along with the reference standard naproxen. The 50 percentage of inhibitory concentration $\left(\mathrm{IC}_{50}-\mu \mathrm{g} / \mathrm{ml}\right.$ of extract $)$ values of ethanol fraction from both stem and root extract was found to be in DPPH- $\left(\mathrm{IC}_{50}: 32 \pm 0.07 \& 28 \pm 0.02\right)$, ABTS- $\left(\mathrm{IC}_{50}\right.$ : $115 \pm 0.22 \& 120 \pm 0.06)$, NO- $\left(\mathrm{IC}_{50}: 13 \pm 0.05 \& 47 \pm 0.13\right), \mathrm{H}_{2} \mathrm{O}_{2^{-}}$ $\left(\mathrm{IC}_{50}: 21 \pm 0.08 \& 28 \pm 0.09\right)$, TAA- (PI: 73 $\left.\pm 0.16 \& 66 \pm 0.22\right)$ and the protein denaturation assay showed the ethanol fraction has protective activity levels of $220 \pm 0.03 \& 277 \pm 0.22$ in stem and root extracts respectively. Results obtained from this study suggested that both stem and root extracts of CQ possesses potential antioxidant and anti-inflammatory properties.
\end{abstract}

Keywords: Cissus quadrangularis, Free Radicals, Antioxidants, Inflammation

\section{INTRODUCTION}

Free radicals are unstable molecules and they are highly reactive to other stable molecules due to the unpaired electrons on their valence shell. Reactive Oxygen and Nitrogen species are most prevalent radicals generated in our system [1]. Oxidative stress is interconnected with most of the life-threatening diseases [2]. It occurs due to various internal and external physiological processes. Normally our system has defense antioxidant mechanism against radicals. But, during the overproduction of radicals or mal function of the antioxidant system, they fail to scavenge all the radicals and make the cells vulnerable to damage [3]. Based on the type of molecules, they occur in different forms like hydroxide, superoxide or hydrogen peroxide radicals. The principles of progression of diseases like cancer, atherosclerosis, diabetes, Alzheimer, arthritis etc., due to free radicals is revealed by researchers. Indeed, almost all medicinal plants are having effective radical scavengers in it, since it can possibly stabilize these diseases by neutralizing the free radical generation.
The ROS accompany various diseases by causing local inflammations and progress the diseases to even worse. Inflammation is a natural innate immune mechanism response against infection or damage. The inflammation alert immune cells to accumulate in the affected site to defend antigen and treat the damage. It causes pain, swelling and redness at the site may leads functionality loss for some period [4]. It can be managed by cold/ heat therapy and anti-inflammatory medications. NSAIDs are most commonly used medications for patients with inflammation. NSAIDs, such as ibuprofen, naproxen, diclofenac, celecoxib and etoricoxib are COX-2 inhibitors, which reduces inflammation by blocking the production of prostaglandin (PGE2). But NSAIDs are may not be suitable for treating inflammation in asthma patients and patients with peptic ulcer, heart attack or stroke. In addition, this medication may also cause serious stomach problems, such as internal bleeding in some patients. Some studies suggested that the prolonged consumption of NSAID can break down the protection barriers in stomach, which protects against acids. Recently there has been an increasing interest in natural therapeutics because of their wide acceptance and reliability. More than $80 \%$ of people in developing countries prefers natural medicine for their primary health. The use of many herbs for treatment of various ailments has been documented in Ayurveda, a medical system practiced in India.

The most eminent anti-inflammatory drugs in Ayurveda which also has been scientifically proved Zinziber officinalis [5], Curcuma longa [6], Ajuga bracteosa [7], Boswellia serrata, Withania somnifera [8], Vitex negundo [9], Tripterygium wilfordii [10], Semecarpus anacardium, Aesculus hippocastanum, Bacopa monnieri [11], Cardiospermum halicacabum [12], Tinospora cordifolia [13], Justicia gendarussa [14], Glycyrrhiza glabra [15], Emblica officinalis, Harpagophytum procumbens [16]. Ananus comosus [17], Calopltyllum inophyllum [18], Carum copticum [19], Commiphora wighitii [20], Mangifera indica [21], Pergularia daemia [22], Piper longum [23], Plumbago Zeylanica [24], Ricinus communis [25], Rubia cordifolia are some notable conventional therapeutic plants evidently proved for their antioxidant, anti-inflammatory and antiarthritic properties. 


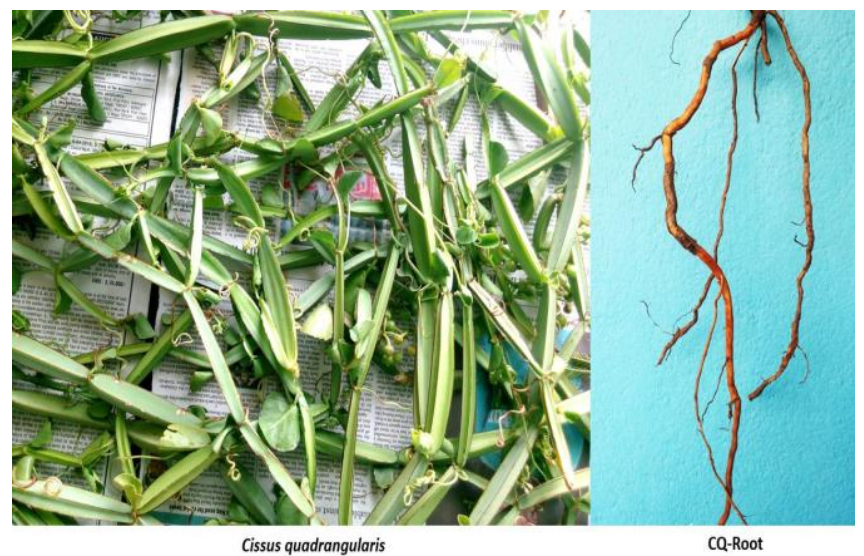

Fig. 1 Cissus quadrangularis Stem and Root

For this study we have chosen the plant Cissus quadrangularis (Fig. 1) which is commonly known as Veldt grape and conventionally used to treat bone related complications, obesity and gastrointestinal disorders. Though, there has been some preliminary reports about the medicinal properties of the CQ stem, the properties of the root are not yet discussed. Since we have planned to analyze the free radical scavenging and anti-inflammatory properties of both stem and root extracts of CQ through in vitro assays.

\section{MATERIALS AND METHOD}

\section{A. Sample Preparation}

The whole plant CQ was collected from Pudukkottai District, Tamil Nadu and authenticated (SJCBOT2565) at St. Joseph's College, Tiruchirappalli. The young and fresh stem and root were separated and washed with distilled water. Then the plant parts were finely sliced and dried in lyophilizer for 24 hours at $-50{ }^{\circ} \mathrm{C}$ with the vacuum pressure of $0.1 \mathrm{mbar}$. Further, the dried sample was powdered and different polar/ less polar components from the plant were extracted using soxhlet and agitated extraction. For this study, hexane, ethanol, methanol, and water were used to perform extraction. The percentage of yield was calculated for all the extracts (Table I)

TABLE I PERCENTAGE OF YIELD OBTAINED FROM DifFERENT SOLVENT EXTRACTS OF CQ

\begin{tabular}{|c|l|c|c|}
\hline \multirow{2}{*}{ S. No. } & \multirow{2}{*}{ Solvent } & \multicolumn{2}{|c|}{ Yield Percentage (\%) } \\
\cline { 3 - 4 } & & CQ-Stem & CQ-Root \\
\hline 1 & Hexane & 3 & 4.4 \\
\hline 2 & Ethanol & 17.6 & 11.7 \\
\hline 3 & Methanol & 18.4 & 12.2 \\
\hline 4 & Aqueous & 12.6 & 9.3 \\
\hline
\end{tabular}

\section{B. Antioxidant Assays}

The extracts were dissolved to their respective solvents to get $1 \mathrm{mg} / \mathrm{ml}$ concentration. In vitro free radical scavenging activity assays were performed for all the samples along with the standard BHT.

\section{DPPH Radical Scavenging Assay}

2,2-diphenyl-1-picrylhydrazyl (DPPH) is a synthetic free radical widely used to study test samples having radical scavenging ability through donating hydrogen. Volumes of 20, 40, 60, 80 and $100 \mu \mathrm{l}$ standard BHT (Sigma Aldrich) and CQ test samples were added to $1 \mathrm{ml}$ of $0.135 \mathrm{mM}$ DPPH (Sigma Aldrich) in methanol and the total volume was made up to $2 \mathrm{ml}$ using methanol. The samples are mixed and kept at dark for 30 minutes. Then the absorbance of the samples of each concentration was measured at $517 \mathrm{~nm}$ using Systronics 2202 double beam spectrophotometer [26]. The percentage of inhibition was calculated using the equation, Percentage of Inhibition $=($ Abs. of Control $)-($ Abs. of Sample)/ (Abs. of Control) x100

\section{ABTS Radical Scavenging Assay}

2,2'-azino-bis (3-ethylbenzothiazoline-6-sulphonic acid) (ABTS-Sigma Aldrich) get oxidized with potassium per sulfate (Hi-media) and produces free radical cation ABTS ${ }^{*+}$. $\mathrm{ABTS}^{*+}$ stock was prepared by adding $7 \mathrm{mM}$ ABTS to the $2.4 \mathrm{mM}$ potassium persulfate. The solution was kept in dark for 12 hours for radical generation. Working solution of ABTS was prepared by diluting $1 \mathrm{ml}$ of stock with methanol until obtain the absorbance of $0.706 \pm 0.001$ at $734 \mathrm{~nm}$. Five different volumes ranging 50 to $250 \mu \mathrm{l}$ of sample along with standard were added to the $1 \mathrm{ml}$ of $\mathrm{ABTS}^{*+}$ and the total volume of the solution was made up to $2 \mathrm{ml}$ with methanol [27]. The absorbance was read at $734 \mathrm{~nm}$. The percentage of inhibition was calculated by following the equation,

Percentage of Inhibition $=($ Abs. of Control $)-($ Abs. of Sample)/ (Abs. of Control) x100

\section{E. Nitric Oxide Radical Scavenging Assay}

Nitric Oxide (NO) is a reactive nitrogen species formed by reacting with molecular oxygen. Incubating sodium nitroprusside (Sigma Aldrich) in phosphate buffer saline yields NO radical. Under aerobic condition NO radical reacts with oxygen and produces nitrate/ nitrite. This can be analyzed by Marcocci, 1994 [28] method. Briefly, different volume of samples $(20,40,60,80,100 \mu \mathrm{l})$ was added to the $2 \mathrm{ml} 10 \mathrm{mM}$ sodium nitroprusside with $0.5 \mathrm{ml}$ PBS (pH 7.4). Tubes were incubated at $25{ }^{0} \mathrm{C}$ for 150 minutes. $0.5 \mathrm{ml}$ of incubated solution was taken and $0.5 \mathrm{ml}$ of griess reagent (Sigma Aldrich) was added and the mixture was incubated for 30 minutes at room temperature and the absorbance was measured at $546 \mathrm{~nm}$. Percentage of inhibition was calculated as by following formula,

Percentage of Inhibition $=($ Abs. of Control $)-($ Abs. of Sample)/ (Abs. of Control) x100

\section{F. $\mathrm{H}_{2} \mathrm{O}_{2}$ Scavenging Assay}

Hydrogen peroxide $\left(\mathrm{H}_{2} \mathrm{O}_{2}\right)$ radical scavenging assay was performed by adopting the protocol of Ruch, 1989 [29] with some modifications. Briefly, $0.6 \mathrm{ml}$ of $4 \mathrm{mM} \mathrm{H} \mathrm{H}_{2} \mathrm{O}_{2}$ (Sigma Aldrich) prepared in $50 \mathrm{mM}$ phosphate buffer was added 
with different concentrations $(10,20,30,40 \& 50 \mu l)$ of CQ extracts. The final volume was made to $1 \mathrm{ml}$ by adding $50 \mathrm{mM}$ phosphate buffer $(\mathrm{pH} 7.4)$ to all tubes. The absorbance was red after 10 minutes at $230 \mathrm{~nm}$ and radical scavenging activity was calculated by following equation.

Percentage of Inhibition $=(1)-($ Abs. of Sample $) /($ Abs. of Control) x100

\section{G. Total Antioxidant Activity}

The total antioxidant activity of the plant extracts was analyzed by following the method of Prieto, 1999 [30]. 0.1 $\mathrm{ml}$ of each extracts and standard ascorbic acid were added to the $1 \mathrm{ml}$ mixture of $0.6 \mathrm{M}$ sulfuric acid (Sigma AldrichEmplura), 28mM sodium phosphate (Sigma Aldrich) and $4 \mathrm{mM}$ ammonium molybdate (Sigma Aldrich). The tubes were incubated at $95{ }^{\circ} \mathrm{C}$ for 90 minutes. Thereupon, the tubes were cooled to room temperature and absorbance was measured at $765 \mathrm{~nm}$. The percentage of inhibition was calculated by the following equation.

Percentage of Inhibition $=($ Abs. of Control $)-($ Abs. of Sample)/ (Abs. of Control) x100

\section{H. Ferric Reducing Power Assay}

Ferric Reducing Power Assay was performed by following the protocol proposed by Oyaizu, 1986. 20 to $100 \mu \mathrm{l}$ of the samples and standard BHT were mixed with $2.5 \mathrm{ml}$ of $0.2 \mathrm{M}$ phosphate buffer ( $\mathrm{pH}$ 6.6). Then $2.5 \mathrm{ml}$ of $1 \%$ Potassium ferricyanide (Sigma Aldrich) was added and the mixture was incubated at $50{ }^{\circ} \mathrm{C}$ for 20 minutes. After incubation 2.5 $\mathrm{ml}$ of trichloroacetic acid was added to the tubes and centrifuged at $3000 \mathrm{rpm}$ for 10 mins. $2.5 \mathrm{ml}$ of distilled water and $0.5 \mathrm{ml}$ of $0.1 \%$ ferric chloride was subsequently added to the supernatant and the absorbance was measured at $700 \mathrm{~nm}$.

\section{Anti-Inflammatory Assay}

The in vitro anti-inflammatory/ Phospomolybdenum assay (PMA) was performed by adopting the protocol of Padmanabhan, 2012 [31]. Five different volumes of CQ extracts ranging 100-500 $\mu \mathrm{l}$ was added to $3 \mathrm{ml}$ phosphate buffer saline. $2 \mathrm{ml}$ of egg albumin was added, blended and incubated at $25{ }^{0} \mathrm{C}$ for 15 minutes. The tubes were transferred to $65{ }^{\circ} \mathrm{C}$ in water bath for 12 minutes. Samples were then cooled, and absorbance was measured at $660 \mathrm{~nm}$. The percentage inhibition of protein denaturation was analyzed by the following formula.

Percentage of Inhibition $=($ Abs. of Control $)-($ Abs. of Sample)/ (Abs. of Control) x100

\section{J. Statistical Analysis}

The triplicate result data of each extracts were analyzed using SPSS software package (IBM SPSS, New York). The one-way analysis of variance (ANOVA) with Duncan's post hoc test was performed to analyze the differences between mean and the level of significance was set to $\mathrm{p}<0.05$.

\section{RESULTS AND DISCUSSION}

The ethanol and methanol of both stem and root extract yielded high levels of dry fractions. The percentage of yield was calculated and presented in the table 1 . Further, the in vitro antioxidant activity assays were also showed ethanol fractions of stem and root extract possesses higher free radical scavenging ability than other extracts. The fifty percent inhibition of different free radicals by ethanol fraction was found to be DPPH- $\left(\mathrm{IC}_{50}: 32 \pm 0.07 \& 28 \pm 0.02\right)$ and ABTS- $\left(\mathrm{IC}_{50}: 115 \pm 0.22 \& 120 \pm 0.06\right)$. Both DPPH and ABTS radical cation are popular synthetic radicals used to test the efficacy of neutralizing effect of the drug by means of donating hydrogen to the radical. Since from the results the ethanolic fractions of both CQ stem and root showed higher level of neutralizing effect against those radicals. NO is a reactive nitrogen species, which produces more vulnerable apoptotic substance peroxynitrate while reacting with superoxide. The levels of NO radical inhibition were found to be $\left(\mathrm{IC}_{50}: 13 \pm 0.05 \& 47 \pm 0.13\right)$ in stem and root ethanolic fractions. Likewise, the activities against $\mathrm{H}_{2} \mathrm{O}_{2}$ and TAA was found to be $\left(\mathrm{H}_{2} \mathrm{O}_{2}-\mathrm{IC}_{50}: 21 \pm 0.08 \& 28 \pm 0.09\right)$, (TAA-PI: $73 \pm 0.16 \& 66 \pm 0.22$ ). All extracts except hexane showed moderate levels of ferric reducing power activity (Fig. 2).
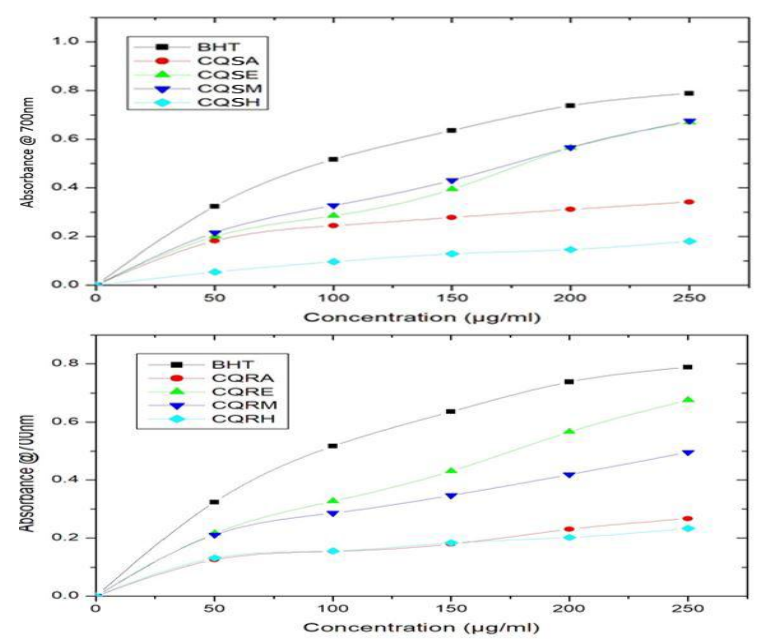

Fig. 2 Ferric Reducing Power Assay

There have been numerous evidences on free radicals as a risk factor for multiple life-threatening diseases. Role of free radicals in the development of insulin insensitivity in type II diabetic patients are discussed by [32, 33]. Their influence on some neurodegenerative diseases like Parkinson and Alzheimer's disease were also proved by [34,35]. Further, there have been certain reports stating the involvement of them in the development of colorectal, prostate, breast, bladder cancers and even some regular complications like, hypertension, atherosclerosis, cataract and asthma [36]. From the Phosphomolybdenum assay (PMA) we observed same kind of activities (Table II). The ethanol fraction followed by methanol extract showed fifty percentage of inhibition at $220 \pm 0.03 \& 277 \pm 0.22$ on CQSE and CQRE respectively. 
TABLE II IC50 VALUES Of ANTIOXIDANT AND ANTI-INFLAMMATORY ASSAYS

\begin{tabular}{|l|c|c|c|c|c|c|}
\hline \multirow{2}{*}{ Sample } & \multicolumn{7}{c|}{ IC50 values $(\boldsymbol{\mu g} / \mathbf{m L})$} \\
\cline { 2 - 7 } & DPPH & ABTS & NO & $\mathbf{H}_{2} \mathbf{O}_{2}$ & TAA \% (PI) & PMA \\
\cline { 1 - 7 } BHT & $9 \pm 0.02$ & $53 \pm 0.14$ & $40 \pm 0.15$ & $16 \pm 0.04$ & - & - \\
\cline { 1 - 7 } Ascorbic acid & - & - & - & - & $78 \pm 0.2$ & - \\
\cline { 1 - 7 } Naproxen & - & - & - & - & - & $196 \pm 0.07$ \\
\cline { 1 - 7 } CQSH & $52 \pm 0.09$ & 0 & $80 \pm 0.05$ & $43 \pm 0.01$ & $22 \pm 0.14$ & 0 \\
\hline CQSE & $32 \pm 0.07$ & $115 \pm 0.22$ & $13 \pm 0.05$ & $21 \pm 0.08$ & $73 \pm 0.16$ & $220 \pm 0.03$ \\
\hline CQSM & $36 \pm 0.12$ & $122 \pm 0.53$ & $14 \pm 0.08$ & $21 \pm 0.05$ & $65 \pm 0.08$ & $264 \pm 0.12$ \\
\hline CQSA & $56 \pm 0.02$ & $160 \pm 0.18$ & $17 \pm 0.05$ & $29 \pm 0.03$ & $48 \pm 0.25$ & $310 \pm 0.06$ \\
\hline CQRH & 0 & $235 \pm 0.33$ & 0 & 0 & $14 \pm 0.3$ & 0 \\
\hline CQRE & $28 \pm 0.02$ & $120 \pm 0.06$ & $47 \pm 0.13$ & $28 \pm 0.09$ & $66 \pm 0.22$ & $277 \pm 0.22$ \\
\hline CQRM & $49 \pm 0.05$ & $136 \pm 0.21$ & $47 \pm 0.08$ & $33 \pm 0.02$ & $49 \pm 0.1$ & $235 \pm 0.1$ \\
\hline CQRA & 0 & $150 \pm 0.14$ & $84 \pm 0.07$ & $35 \pm 0.04$ & $27 \pm 0.2$ & $286 \pm 0.05$ \\
\hline
\end{tabular}

IC50-Fifty percentage of inhibitory concentration; PI-Percentage of inhibition; BHT-Butyl-hydroxy toluene;

CQS- Cissus quadrangularis stem; CQR-Cissus quadrangularis root; H-Hexane; E-Ethanol; M-Methanol; A-Aqeous fraction

Fruits and vegetables are precious sources of antioxidants and anti-inflammatory compounds. CQ is one among the vegetables of Indian diet, which has numerous health benefits like to treat gastrointestinal problems, obesity and all bone related complications. Identifying the active constituents of CQ which is responsible for their medicinal would be a future perspective.

\section{CONCLUSION}

The most commonly used drugs of modern medicine such as digitalis, aspirin, penicillin, some steroidal drugs have originated from natural sources. Instead of single active compound, conventional treatment option prefers whole plant or formulations of multi targeted medicines to attain fast recovery from any kinds of illness. The present study proved that the both stem and root extracts of CQ holds excelled free radical scavenging ability and antiinflammatory properties. Recently, there has been a resurgence of interest among people in the utilization of natural products. In such a way, CQ is a healthy option to add up in our diet to strengthen our anti-oxidant mechanism and health.

\section{REFERENCES}

[1] M. Lawson, K. Jomova, P. Poprac, K. Kuča, K. Musílek, and M. Valko, $1^{\text {st }}$ Ed., Nutritional Antioxidant Therapies: Treatments and Perspectives, Al-Gubory, Kaïs Hussain, Laher Ismail., Ed. SpringerCham, 2017.

[2] H. Sies, C. Berndt, and D. P. Jones, "Oxidative stress", Annu Rev Biochem., Vol. 20, No. 86, pp. 715-48, 2017.

[3] P. Poprac, K. Jomova, M. Simunkova, V. Kollar, C. J. Rhodes, and M. Valko, "Targeting free radicals in oxidative stress-related human diseases", Trends Pharmacol Sci., Vol. 38, No. 7, pp. 592-607, 2017.

[4] E. Hyun, M. Bolla, M. Steinhoff, J. L. Wallace, P. Del Soldato, and N. Vergnolle, "Anti-inflammatory effects of nitric oxide-releasing hydrocortisone NCX 1022, in a murine model of contact dermatitis", Br J Pharmacol., Vol. 143, No. 5, pp. 618-625, 2004.
[5] M. Thompson, K. K. Al-Qattan, S.W. Al-Sawan, M.A. Al-Nageeb, and I. Khan, "The use of ginger as a potential anti-inflammatory and antithrombotic agent, Prostagladin, leukotriens and essential fatty acids", Prostaglandins Leukot Essen Fatty Acids., Vol. 67, No. 6, pp. 475-478, 2002.

[6] Y. Abe, S. H. Hashimoto, and T. Horie, "Curcumin inhibition of inflammatory cytokine production by human peripheral blood monocytes and alveolar macrophages", Pharmacol Res., Vol. 39, No. 1, pp. 41-47, 1999.

[7] G. Kaithwas, R. Gautam, S. M. Jachak, and A. Saklani, "Antiarthritic effects of Ajuga bracteosa Wall ex Benth. in acute and chronic models of arthritis in albino rats", Asian Pac J Trop Biomed., Vol. 2, No. 3, pp. 185, Mar. 2012.

[8] B. Jayaprakasam, and M. G. Nair, "Cyclooxygenase-2 enzyme inhibitory withanolides from withania somnifera leaves", Tetrahedran., Vol. 59, No. 6, pp. 841-849, 2002.

[9] A. S. Chawla, A. K. Sharma, S. S. Handa, and K. L. Dhar, "Chemical investigation and anti-inflammatory activity of Vitex negundo seeds: Part I", J Nat Prod., Vol. 55, No. 2, pp. 773-776, 1992.

[10] A. C. Allison, R. Cacabelos, V. R. Lombardi, X. A. Álvarez, and C. Vigo, "Celastrol, a potent antioxidant and anti-inflammatory drug, as a possible treatment for Alzheimer's disease", Prog NeuroPsychopharmacol Biol Psychiatry., Vol. 25, No. 7, pp. 1341-1357, Oct. 2001.

[11] S. K. Bhattacharya, and S. Ghosal, "Anxiolytic activity of a standardized extract of Bacopa monniera: an experimental study", Phytomedicine, Vol. 5, No. 2, pp. 77-82, 1998.

[12] M. M. Shabi, R. Dhevi, K. Gayathri, U. Subashini, G. V. Rajamanickam, and G. P. Dubey, "C. halicacabum (Linn): investigations on anti-inflammatory and analgesic effect", Bulgarian J Vet Med., Vol.12, No. 3, pp. 171-177, 2009.

[13] A. K. Rawal, D. K. Nath, N. Yadav, S. Pande, S. U. Meshram, and S. K. Biswas, "Rubia cordifolia, Fagonia cretica linn and Tinospora cordifolia exert anti-inflammatory properties by modulating platelet aggregation and VEGF, COX-2 and VCAM gene expressions in rat hippocampal slices subjected to ischemic reperfusion injury", Int $J$ Appl Res Nat Prod., Vol. 2, No. 1, pp. 19-26, 2009.

[14] J. Paval, S. K. Kaitheri, B. K. Potu, S. Govindan, R. S. Kumar, S. N. Narayanan, and S. Moorkoth, "Anti-arthritic potential of the plant Justicia gendarussa Burm F”, Clinics., Vol. 64, No. 4, pp. 357-362, 2009.

[15] A. Herold, L. Cremer, A. Călugaru, V. Tamaş, F. Ionescu, S. Manea and G. Szegli, "Hydroalcoholic plant extracts with anti-inflammatory activity", Roum Arch Microbiol Immunol., Vol. 62, No. 2, pp. 117129, 2003. 
[16] G. McGregor, B. Fiebich, A. Wartenberg, S. Brien, G. Lewith, and T. Wegener, "Devil's claw (Harpagophytum procumbens): an antiinflammatory herb with therapeutic potential", Phytochemistry Rev., Vol. 4, No. 1, pp. 47-53, 2005.

[17] E. R. Secor Jr, W. F. Carson, M. M. Cloutier, L. A. Guernsey, C. M. Schramm, C. A. Wu, and R. S. Thrall, "Bromelain exerts antiinflammatory effects in an ovalbumin-induced murine model of allergic airway disease", Cell Immunol., Vol. 237, No. 1, pp. 68-75, 2005.

[18] C. Gopalakrishnan, D. Shankaranarayanan, S. K. Nazimudeen, S. Viswanathan, and L. Kameswaran, "Anti-inflammatory and CNS depressant activities of xanthones from Calophyllum inophyllum and Mesua ferrea", Indian J Pharmacol., Vol. 12, No. 3, pp. 181, 1980.

[19] C. Thangam, and R. Dhananjayan, "Antiinflammatory potential of the seeds of Carum copticum Linn.", Indian J Pharmacol., Vol. 35, No. 6, pp. 388-391, 2003.

[20] M. S. Bagul, H. Srinivasa, N. S. Kanaki, and M. Rajani, "Antiinflammatory activity of two Ayurvedic formulations containing guggul”, Indian J Pharmacol., Vol. 37, No. 6, pp.399, 2005.

[21] M. Knödler, J. Conrad, E. M. Wenzig, R. Bauer, M. Lacorn, U. Beifuss, R. Carle, and A. Schieber, "Anti-inflammatory 5-(11' Zheptadecenyl)-and 5-(8' Z, 11' Z-heptadecadienyl)-resorcinols from mango (Mangifera indica L.) peels", Phytochemistry., Vol. 69, No. 4, pp. 988-993, 2008

[22] N. G. Sutar, Y. P. Sharma, P. N. Kendre, M. K. Panigrahi, T. A. Deshmukh, and N. P. Jain, "Anti-inflammatory activity of whole plant of pergularia daemia linn. in albino rats", J Herb Med Toxicol., Vol. 3, No. 1, pp. 131-132, 2009.

[23] J. R. Stöhr, P. G. Xiao, and R Bauer, "Constituents of Chinese Piper species and their inhibitory activity on prostaglandin and leukotriene biosynthesis in vitro", J Ethnopharmacol., Vol. 75, No. 3, pp. 133139, 2001

[24] K. D. Arunachalam, P. Velmurugan, and R. B. Raja, "Antiinflammatory and cytotoxic effects of extract from Plumbago zeylanica", Afr J Microbiol Res., Vol. 4, No. 12, pp. 1239-1245, 2010.

[25] M. R. Khan, G. Ndaalio, M. H. Nkunya, and H. Wevers, "Studies on the rationale of African traditional medicine. Part II. Preliminary screening of medicinal plants for anti-gonococci activity", J Sci Ind Res., Vol. 27, No. 516, pp. 189-92, 1978.

[26] W. Brand-Williams, M. E. Cuvelier, and C. L. Berset, "Use of a free radical method to evaluate antioxidant activity", LWT-Food Sci Technol., Vol. 28, No. 1, pp. 25-30, 1995.
[27] M. Ozgen, R. N. Reese, A. Z. Tulio, J. C. Scheerens, and A. R. Miller, "Modified 2, 2-azino-bis-3-ethylbenzothiazoline-6-sulfonic acid (ABTS) method to measure antioxidant capacity of selected small fruits and comparison to ferric reducing antioxidant power (FRAP) and 2, 2 '-diphenyl-1-picrylhydrazyl (DPPH) methods", $J$ Agric Food Chem., Vol. 54, No. 4, pp. 1151-1157, 2006.

[28] L. Marcocci, J. J. Maguire, M. T. Droylefaix, and L. Packer, "The nitric oxide-scavenging properties of Ginkgo biloba extract EGb 761”, Biochem Biophys Res Commun., Vol. 201, No. 2, pp.748-755, 1994.

[29] R. J. Ruch, S. J. Cheng, and J. E. Klaunig, "Prevention of cytotoxicity and inhibition of intercellular communication by antioxidant catechins isolated from Chinese green tea", Carcinogenesis., Vol. 10, No. 6, pp. 1003-1008, 1989.

[30] P. Prieto, M. Pineda, and M. Aguilar, "Spectrophotometric quantitation of antioxidant capacity through the formation of a phosphomolybdenum complex: specific application to the determination of vitamin”, E. Anal Biochem., Vol. 269, No. 2, pp. 337-341, 1999.

[31] P. Padmanabhan and S N. Jangle, "Evaluation of DPPH radical scavenging activity and reducing power of four selected medicinal plants and their combinations", Int J Pharm Sci Drug Res., Vol. 4, No. 2, pp. 143-146, 2012.

[32] L. W. Oberley, "Free radicals and diabetes", Free Radic Biol Med., Vol. 5, No.2 pp. 11-24, 1988.

[33] N. Bashan, J. Kovsan, I. Kachko, H. Ovadia, and A Rudich, "Positive and negative regulation of insulin signaling by reactive oxygen and nitrogen species", Physiol Rev., Vol. 89, No. 1, pp. 27-71, 2009.

[34] S. Olivieri, A. Conti, S. Iannaccone, C. V. Cannistraci, A. Campanella, M. Barbariga, F. Codazzi, I. Pelizzoni, G. Magnani, M. Pesca, and D Franciotta, "Ceruloplasmin oxidation, a feature of Parkinson's disease CSF, inhibits ferroxidase activity and promotes cellular iron retention", J Neurosci., Vol. 31, No. 50, pp. 1856818577,2011

[35] D. A. Butterfield, M. Perluigi, and R. Sultana, "Oxidative stress in Alzheimer's disease brain: new insights from redox proteomics", Euro J Pharm., Vol. 545, No. 1, pp. 39-50, 2006.

[36] A. Phaniendra, D. B. Jestadi, and L. Periyasamy, "Free radicals: properties, sources, targets, and their implication in various diseases", Indian J Clin Biochem., Vol. 30, No. 1, pp. 11-26, 2015. 